\title{
Comparative review of the blood pressure-lowering and cardiovascular benefits of telmisartan and perindopril
}

This article was published in the following Dove Press journal:

Vascular Health and Risk Management

5 April 2014

Number of times this article has been viewed

Ji-Guang Wang'

Eduardo Pimenta ${ }^{2}$

Frank Chwallek ${ }^{3}$

'Centre for Epidemiological Studies and Clinical Trials, Shanghai Institute of Hypertension, Ruijin Hospital, Shanghai Jiaotong University School of Medicine, Shanghai, People's Republic of China; ${ }^{2}$ Boehringer Ingelheim, Sydney, NSW, Australia; ${ }^{3}$ Boehringer Ingelheim Pharma, Biberach an der Riss, Germany
Correspondence: Ji-Guang Wang Centre for Epidemiological Studies and Clinical Trials, Shanghai Institute of Hypertension, Ruijin Hospital, Shanghai Jiaotong University School of Medicine, 197 2nd Road, Shanghai 200025, People's Republic of China

Tel +862164370045

Fax +862164662193

Email jiguangwang@aim.com
Abstract: Hypertension is a major cardiovascular (CV) risk factor, and blood pressure (BP)lowering treatment substantially reduces the risk. This review compares the available clinical evidence from the BP-lowering and CV-outcome studies of telmisartan and perindopril, which are among the most intensively studied members of their respective classes. The PubMed database was searched for telmisartan and perindopril publications meeting the following criteria: 1) head-to-head comparison trials for BP lowering; and 2) CV-outcome studies (ie, ones with a $\mathrm{CV}$ event, mortality, or hospitalization outcome) in patients with CV risk factors but without heart failure. In comparative trials, telmisartan treatment resulted in significantly higher reduction in trough BP and mean ambulatory diastolic BP for the last 8 hours of the dosing interval compared with perindopril. In mainly placebo-controlled CV-outcome studies in patients with hypertension, CV benefits with perindopril were associated with large reductions in BP. There were no $\mathrm{CV}$ outcome studies with telmisartan in patients with hypertension. The beyond-BP-lowering CV-protective benefits of telmisartan were demonstrated in the active-controlled ONTARGET (ONgoing Telmisartan Alone and in combination with Ramipril Global Endpoint Trial) trial, which included patients with controlled BP at baseline. In general, the trials discussed in this review reinforce the fact that perindopril and telmisartan are two long-acting antihypertensive drugs that reduce BP over 24 hours, and are the best-evidenced drugs in their class with proven CV protection. It is also clear that the benefits are not a "class effect", and vary between the different drugs within each class. Hence, the best approach for treatments tailored to individual patient needs should be evidence-based specific drugs, rather than a drug-class recommendation for achieving therapeutic targets.

Keywords: hypertension, antihypertensive therapy, clinical outcome, renin-angiotensin system inhibitors, angiotensin-converting enzyme inhibitor, angiotensin-receptor blocker

\section{Introduction}

The renin-angiotensin system (RAS) is an important mediator of blood volume, arterial pressure, and cardiac and vascular function. ${ }^{1,2}$ Angiotensin II is a key component of the RAS, which acts via the $\mathrm{AT}_{1}$ receptor at every step of the cardiovascular $(\mathrm{CV})$ continuum. ${ }^{3,4}$ The angiotensin-converting enzyme (ACE) inhibitors and angiotensin II receptor blockers (ARBs) are two different classes of agents that target the RAS via their effect on the production or action of angiotensin II. ${ }^{1}$ Both ACE inhibitors and ARBs prevent $\mathrm{CV}$ disease by lowering blood pressure (BP), but also have beyondBP-lowering benefits, and therefore are now considered first-line treatments for hypertensive target-organ damage and progressive renal disease..$^{5-8}$

ACE inhibitors and ARBs have been shown in head-to-head comparison trials to have comparable $\mathrm{CV}$ protective effects. However, ARBs are associated with fewer 
adverse effects and better patient compliance. ${ }^{9,10}$ Both ACE inhibitors and ARBs exert multiple antiatherogenic actions, and reduce clinical events in high-risk participants. Their use is recommended in guidelines for the reduction of $\mathrm{CV}$ risk in patients with diabetes and hypertension, ${ }^{11}$ and in hypertensive patients with microalbuminuria, renal dysfunction, end-stage renal disease, and diabetes mellitus. ${ }^{12}$

Although ACE inhibitors and ARBs are generally comparable when evaluating average class effects, members of both classes differ substantially from one another in their pharmacology. Therefore, relying on class averages may not reveal a complete picture. This was acknowledged in the recent European Society of Cardiology (ESC) guidelines on heart failure, ${ }^{13}$ which reviewed evidence for individual drugs rather than drug classes. With this in mind, we reviewed the evidence for $\mathrm{CV}$ protection with two of the most widely studied representatives of the two classes - telmisartan and perindopril. Both have a long elimination half-life of $>20$ hours for telmisartan and $\sim 17$ hours for perindopril, are dosed once daily, and have sustained efficacy for at least 24 hours. ${ }^{14,15}$ Telmisartan has high receptor-binding affinity and slow dissociation from the $\mathrm{AT}_{1}$ receptor. ${ }^{16}$ Binding of perindoprilat, the active metabolite of perindopril, to plasma proteins, principally the ACE, is $20 \%$ and is concentrationdependent. ${ }^{14}$ Elimination of perindoprilat is decreased in the elderly and in patients with heart or renal failure. The elimination of telmisartan is unchanged in these patients. Telmisartan and perindopril have proven efficacy and tolerability in the treatment of hypertension. ${ }^{17-21}$

The objective of this review was to compare the available clinical evidence from BP-lowering and CV-outcome studies of telmisartan and perindopril. We chose to review and assess controlled, randomized trials, excluding metaanalyses. This is aligned with the concerns voiced in the recent European Society of Hypertension (ESH)/ESC 2013 guidelines ${ }^{12}$ that the relative superiority of one class of agents over another seen in meta-analysis are largely dependent on the selection bias of trials.

\section{Study selection}

The PubMed database was searched for all primary publications of studies of telmisartan and perindopril meeting the following criteria: 1) head-to-head comparison of BP-lowering trials; and 2) CV-outcome studies (ie, ones with a CV event, mortality, or hospitalization outcome) in patients with $\mathrm{CV}$ risk factors but without heart failure.

Five studies that compared telmisartan and perindopril were identified. Of these, two had BP lowering as the primary end point,,$^{22,23}$ and three had other primary end points: 1) to compare the effect on endothelium-dependent vasodilation in the peripheral conduit arteries of patients with essential hypertension; ${ }^{24} 2$ ) to compare the effect on left ventricular hypertrophy in elderly patients with diabetes mellitus and essential hypertension; ${ }^{25}$ and 3) to compare the effect on endothelial/platelet function and on coagulation/fibrinolysis. ${ }^{26}$ Only the two BP-lowering trials are included in this review.

Six CV-outcome studies for perindopril ${ }^{27-32}$ and three CV-outcome studies for telmisartan ${ }^{33-35}$ were identified from the search. Of these, five studies of perindopril and all three studies of telmisartan are included in the review. One study of perindopril in patients with heart failure was excluded. ${ }^{28}$

\section{Head-to-head comparison trials for BP lowering in patients with mild-to-moderate hypertension}

In the 12-week EVERESTE (EValuation de l'Efficacite RESiduelle du TElmisartan) study in 441 patients, ${ }^{23}$ trough diastolic BP (DBP) was found to be significantly lower in the telmisartan $40 \mathrm{mg}$ group than in the perindopril $4 \mathrm{mg}$ group, both by BP self-measurement (87.6 versus $89.6 \mathrm{mmHg}, P<0.05$ ) and clinic BP measurement ( 88.7 versus $91.3 \mathrm{mmHg}, P<0.005)$ after 12 weeks. Similar findings were observed for trough systolic BP (SBP; BP self-measurement 139.3 versus $143.3 \mathrm{mmHg}$, respectively, $P<0.005$; clinic BP measurement 144.0 versus $148.0 \mathrm{mmHg}$, respectively, $P<0.05$ ). The change from baseline to week 12 in trough DBP was significantly higher in the telmisartan $40 \mathrm{mg}$ group than in the perindopril $4 \mathrm{mg}$ group, both by BP self-measurement $(-6.6 \mathrm{mmHg}$ versus $-5.1 \mathrm{mmHg}$ adjusted between-treatment difference $-1.4 \mathrm{mmHg}, 95 \%$ confidence interval $[\mathrm{CI}]-2.74$ to $-0.14 \mathrm{mmHg} ; P=0.03$ )(Figure 1) and clinic

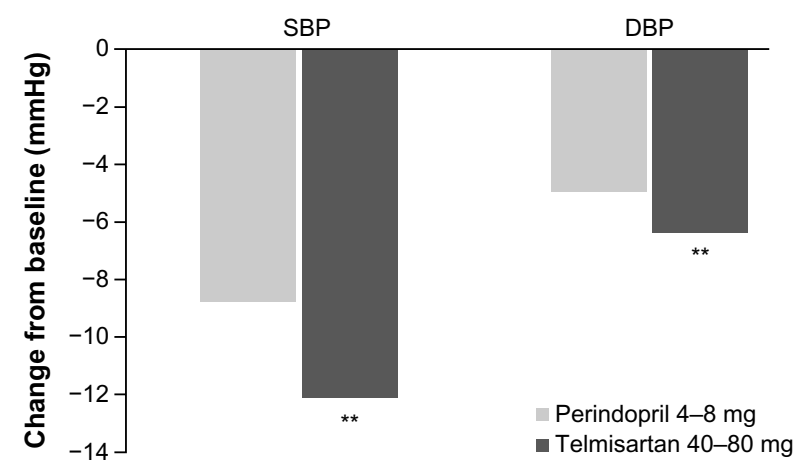

Figure I Reductions in home blood pressure with telmisartan and perindopril. Notes: ${ }^{* *} P<0.01$ vs perindopril. Data from Ragot et al. ${ }^{23}$

Abbreviations: DBP, diastolic blood pressure; SBP, systolic blood pressure. 
BP measurement $(-8.8 \mathrm{mmHg}$ versus $-6.3 \mathrm{mmHg}$, respectively, adjusted between-treatment difference $-2.5 \mathrm{mmHg}, 95 \% \mathrm{CI}$ -4.11 to $-0.89 \mathrm{mmHg} ; P=0.002)$. Similar findings were observed for trough SBP (BP self-measurement $-12.3 \mathrm{mmHg}$ versus $-8.9 \mathrm{mmHg}$, adjusted between-treatment difference $-3.4 \mathrm{mmHg}, 95 \% \mathrm{CI}-5.69$ to $-1.08 \mathrm{mmHg} ; P=0.004)$ (Figure 1) and clinic BP measurement $(-13.9 \mathrm{mmHg}$ versus, $-10.9 \mathrm{mmHg}$, respectively, adjusted between-treatment difference $-3.4 \mathrm{mmHg}, 95 \% \mathrm{CI}-6.24$ to $-0.64 \mathrm{mmHg}$; $P=0.016)$. Cough was reported in a significantly higher percentage of patients on perindopril $(5 \%)$ than telmisartan $(<1 \%, P=0.007)$.

In a prospective, randomized study, 60 patients with mild-to-moderate hypertension (SBP 140-180 mmHg, DBP 90-100 $\mathrm{mmHg}$ ) received telmisartan $80 \mathrm{mg}$ or perindopril $4 \mathrm{mg}$ for 6 weeks. ${ }^{22}$ Mean (standard deviation) clinic BP was reduced from $167.4(9.4) / 102.2(4.7) \mathrm{mmHg}$ at baseline to $139.7(8.3) / 89.8(4.7) \mathrm{mmHg}$ at 6 weeks in the telmisartan $40 \mathrm{mg}$ group, and from 167.6 (6.0)/101.4 (3.9) $\mathrm{mmHg}$ to 141.7 (6.9)/91.3 (5.3) $\mathrm{mmHg}$ in the perindopril $4 \mathrm{mg}$ group. The reduction in mean ambulatory DBP for the last 8 hours of the dosing interval was significantly greater in patients treated with telmisartan compared to those treated with perindopril $(P<0.05)$. A significantly higher percentage of patients in the telmisartan group compared to those in the perindopril group ( $66.6 \%$ versus $46.6 \%$, respectively; $P<0.05$ ) achieved 24-hour DBP values $<85 \mathrm{mmHg}$. Cough was reported in $6.6 \%$ of patients on perindopril and in none on telmisartan treatment.

\section{Cardiovascular-outcome trials}

In PROGRESS (Perindopril pROtection aGainst REcurrent Stroke Study), ${ }^{27} 6,105$ patients with a history of stroke or transient ischemic attack within the previous 5 years were randomized to perindopril $4 \mathrm{mg} /$ day \pm indapamide $2.5 \mathrm{mg}$ /day (except Japan, where $2.0 \mathrm{mg} /$ day was used) or placebo. There was no lower cutoff limit of BP for entry into the trial. Mean BP at baseline was 147/86 mmHg. Over 4 years of follow-up, perindopril \pm indapamide reduced SBP by $9 \mathrm{mmHg}$ and DBP by $4 \mathrm{mmHg}$ compared to placebo. Active treatment reduced the occurrence of fatal and nonfatal stroke (primary end point) by $28 \%$ and major CV complications by $26 \%$. These relative risk reductions were similar in hypertensive and nonhypertensive patients. In a prespecified subgroup analysis, combination therapy was found to reduce elevated baseline BP by $12 / 5 \mathrm{mmHg}$ and stroke risk by $43 \%$. Benefits were similar in hypertensive and nonhypertensive patients. Perindopril monotherapy reduced BP by $5 / 3 \mathrm{mmHg}$. How- ever, despite BP reduction, perindopril monotherapy did not reduce the risk of stroke.

These findings with perindopril monotherapy contrast with those from the HOPE (Heart Outcomes Prevention Evaluation) study, where ramipril reduced stroke by $32 \%$ compared to placebo. ${ }^{36}$ There was no clear evidence of heterogeneity in the size of the hazard ratios between subgroups of participants, defined by time between the qualifying event and enrollment ( $<6$ months or 6 months to 5 years). Because allocation to monotherapy or combination therapy was not randomized, and was at the discretion of the treating physician, it was observed that patients who received combination therapy were younger, more likely to be men, had higher BP at entry, were more likely to be hypertensive, were more likely to have coronary heart disease (CHD), and were recruited sooner after their qualifying cerebrovascular event than those who received monotherapy. ${ }^{27}$ Statistical adjustment for the entry characteristics did not remove the heterogeneity, suggesting $\mathrm{BP}$ and random variation as possible reasons for lack of strokeprevention benefits with perindopril monotherapy. ${ }^{37}$

HYVET (HYpertension in the Very Elderly Trial) ${ }^{38}$ was a randomized, double-blind, placebo-controlled trial conducted in 3,845 patients who were $\geq 80$ years old and had a sustained $\mathrm{SBP} \geq 160 \mathrm{mmHg}$ (mean baseline sitting BP 173.0/90.8 mmHg). Patients received sustained-release indapamide $1.5 \mathrm{mg}$ or placebo. Perindopril ( 2 or $4 \mathrm{mg}$ ) or placebo was added if necessary to achieve the target BP of 150/80 $\mathrm{mmHg}$. At 2 years, $73.4 \%$ of patients were on combination therapy, and $25.8 \%$ were on indapamide alone. Mean sitting $\mathrm{BP}$ was $15.0 / 6.1 \mathrm{mmHg}$ lower in the active-treatment than in the placebo group after 2 years of follow-up. Active treatment was associated with a $30 \%$ reduction in the rate of fatal or nonfatal stroke (primary end point), a 39\% reduction in the rate of death from stroke, a $21 \%$ reduction in the rate of death from any cause, a $23 \%$ reduction in the rate of death from $\mathrm{CV}$ causes, and a $64 \%$ reduction in the rate of heart failure. This study showed that antihypertensive treatment based on indapamide, with or without perindopril, significantly reduced the risks of death from stroke and death from any cause in very elderly patients with hypertension. A 1-year open-label extension of HYVET, ${ }^{39}$ where all patients received active treatment, showed significant differences in total mortality and CV mortality, irrespective of whether patients were previously treated with active drugs or placebo, reinforcing the benefits of early and long-term antihypertensive treatment in the elderly. ${ }^{39}$

Unlike the flexible dosing regimens employed in PROGRESS and HYVET, in the ADVANCE (Action in Diabetes 
and Vascular disease: preterAx and diamicroN-MR Controlled Evaluation) trial, ${ }^{32} 11,140$ patients at least 65 years old with type 2 diabetes were randomized to receive a fixed-dose combination of perindopril/indapamide or placebo in addition to current therapy. There was no BP criterion for inclusion, and average BP at baseline was 145/81 mmHg. Guidelines at that time recommended that target $\mathrm{BP}$ in patients with diabetes should be as low as $130 / 80 \mathrm{mmHg} .{ }^{40}$ Over the 4.3-year follow-up period, BP was reduced by an average of 5.6/2.2 $\mathrm{mmHg}$ with combination treatment compared to placebo. Active treatment reduced the relative risk of major macro- or microvascular events (primary end point, defined as death from $\mathrm{CV}$ disease, nonfatal stroke, nonfatal myocardial infarction $[\mathrm{MI}]$, and new or worsening renal or diabetic eye disease) by $9 \%(P=0.04)$. Reductions were significant for coronary and renal events, but not for total cerebrovascular or diabetic eye events. The separate reductions in macrovascular and microvascular events were similar, but were not independently significant. Active treatment reduced the relative risk of death from $\mathrm{CV}$ disease by $18 \%(P=0.03)$ and death from any cause by $14 \%(P=0.03)$. More than threequarters of participants were receiving nonstudy drugs for lowering BP during the study, and more than $90 \%$ were receiving one or more glucose-lowering agents. ${ }^{32}$ Similar to PROGRESS and HYVET, the observed CV benefits in this study were likely to be due to the greater BP reduction in the perindopril-indapamide group. Furthermore, a non-BP effect of perindopril is rendered less likely by the observation that of the patients randomized to receive placebo, $55 \%$ were actually receiving open-label perindopril at the end of follow-up (an additional 5\% received a different $\mathrm{ACE}$ inhibitor). ${ }^{41}$

In ASCOT-BPLA (Anglo-Scandinavian Cardiac Outcomes Trial - Blood Pressure-Lowering Arm), ${ }^{29}$ 19,257 patients aged 40-79 years with hypertension and at least three additional $\mathrm{CV}$ risk factors were randomized to receive either amlodipine 5-10 $\mathrm{mg}$ or atenolol 50-100 mg. Perindopril 4-8 mg and bendroflumethiazide $1.25-2.5 \mathrm{mg}$ (plus potassium) were added to amlodipine and atenolol treatments, respectively, as required. Mean baseline sitting BP was 164/95 mmHg. BP values were lower throughout the trial in the amlodipine arm (average difference of 2.7/1.9 $\mathrm{mmHg}$ ), with the largest difference at 3 months $(5.9 / 2.4 \mathrm{mmHg})$. The trial was discontinued prematurely, due to significantly lower CV mortality in the amlodipine arm (median follow-up of 5.5 years). The amlodipine-based regimen prevented more major CV events and induced less diabetes than the atenololbased regimen. However, there was no significant difference in the combined outcome of nonfatal MI (including silent MI) and fatal CHD (primary end point) between the two treatment arms, probably because the study was underpowered due to earlier termination of the trial. Perindopril was added to the amlodipine-based regimen no earlier than 6 weeks after initiation of amlodipine treatment. Overall, throughout the trial, a mean $50 \%$ of patients were taking the amlodipine + perindopril combination $(39.1 \%$ of time in the first year and $54.2 \% \geq 6$ years), and $55 \%$ were taking the atenolol + bendroflumethiazide combination.

Although large BP reductions were observed in this study with both combination groups, the reduction achieved in the amlodipine-based treatment group was greater than in the atenolol-based group, especially in the first year. Also, the CV benefits of achievement of BP goals as early as 6 months have been demonstrated in other prospective clinical studies. For example, in the VALUE (Valsartan Antihypertensive Long-term Use Evaluation) trial, ${ }^{42}$ patients with immediate BP response (defined as those patients who when switched from previous treatment to the initial study drug did not have increases in BP by 1 month, or those previously untreated who had an initial decrease in SBP of $10 \mathrm{mmHg}$ or more) had significantly fewer $\mathrm{CV}$ events than nonimmediate responders during the study. ${ }^{43}$ In the CAFE (Conduit Artery Functional Evaluation) study, a large substudy within ASCOT, brachial SBP throughout the study was not significantly different between the treatment groups, but derived central aortic systolic pressure was substantially lower with amlodipine \pm perindopril-based therapy $(4.3 \mathrm{mmHg}, 95 \%$ CI 3.3-5.4; $P<0.0001)$; these differences between brachial and central aortic BP were consistent with time throughout the CAFE study. ${ }^{44}$ This difference in central BP reduction with the amlodipine-based regimen is suggested to have contributed to the differential CV benefits with amlodipine observed in this study. ${ }^{44}$

The results of the ASCOT-BPLA trial also confirmed that most hypertensive patients need at least two antihypertensive drugs to achieve BP targets. ${ }^{29}$ This study, in addition to the ACCOMPLISH (Avoiding Cardiovascular events through COMbination Therapy in Patients LIving with Systolic Hypertension) trial, ${ }^{45}$ are generally considered to provide evidence of the advantages of a calcium-channel blocker plus RAS-inhibitor regime over a $\beta$-blocker/diuretic regime for the prevention of $\mathrm{CV}$ events in high-risk patients.

There are no CV-outcome studies with telmisartan in populations with hypertension. However, the antihypertensive effects of telmisartan have been studied in several trials in patient populations similar to those included in the perindopril CV-outcome trials. ${ }^{46-48}$ Nonetheless, direct 
comparisons cannot be made between these telmisartan and perindopril studies, due to differences in study design and duration of the trials.

\section{Cardiovascular-outcome trials in patients with controlled BP}

The PREAMI (Perindopril and Remodeling in Elderly with Acute Myocardial Infarction) trial ${ }^{30}$ was a doubleblind, randomized, placebo-controlled study in which 1,252 patients $\geq 65$ years old with a left ventricular ejection fraction $\geq 40 \%$ and recent acute MI were randomly assigned to perindopril $8 \mathrm{mg}$ /day or placebo for 12 months. The combined primary end point of death, hospitalization for heart failure, or left ventricular remodeling (considered as $\geq 8 \%$ increase in left ventricular end-diastolic volume measured by quantitative two-dimensional echocardiography) occurred in 181 patients (35\%) on perindopril and 290 patients $(57 \%)$ on placebo (absolute risk reduction $0.22,95 \%$ CI $0.16-0.28$; $P<0.001$ ). A total of $28 \%$ of patients on perindopril and $51 \%$ on placebo experienced left ventricular remodeling. One-year treatment with perindopril $8 \mathrm{mg} /$ day was observed to reduce progressive left ventricular remodeling, but was not associated with better clinical outcomes.

EUROPA (The EUropean trial on Reduction Of cardiac events with Perindopril in patients with stable coronary Artery disease) $)^{31}$ was a randomized, double-blind, placebocontrolled study in which 12,218 patients aged at least 18 years without clinical evidence of heart failure and with evidence of CHD, documented by previous MI, percutaneous or surgical coronary revascularization, or angiographic evidence of at least $70 \%$ narrowing of one or more major coronary arteries, were randomly assigned to perindopril
$8 \mathrm{mg}$ once daily or matching placebo (Table 1). The mean follow-up was 4.2 years. At baseline, mean BP was 137/82, and average BP during double-blind treatment was $5 / 2 \mathrm{mmHg}$ higher in the placebo group than in the perindopril group. Despite BP reduction, perindopril did not reduce the risk of stroke. Perindopril treatment was associated with a $20 \%$ relative risk reduction in the primary end point of $\mathrm{CV}$ death, $\mathrm{MI}$, or cardiac arrest versus placebo ( 8 versus $10 \%, P=0.0003$ ) (Table 1 and Figure 2A). Although a beneficial effect of perindopril was observed for all individual subcomponents of the primary combined end point, only the risk reduction in "nonfatal MI" reached statistical significance. ${ }^{49}$ In the predefined subgroup of patients with and without previous MI, significant difference was seen only in patients with previous MI. Results were not adjusted for BP reduction, and this reduction in $\mathrm{CV}$ events was suggested to be greater than may be expected for the observed mean BP-reduction difference of $5 / 2 \mathrm{mmHg}$ achieved with perindopril.

The PRoFESS (Prevention Regimen For Effectively avoiding Second Strokes) trial ${ }^{34}$ was a two-by-two factorial design study in which 20,332 patients aged 50 years or older were randomized to telmisartan $80 \mathrm{mg}$ daily or placebo in addition to standard care (either aspirin + extended-release dipyridamole or clopidogrel) at a median time of 15 days after an ischemic stroke. Most (74\%) participants had a history of hypertension, and mean BP at baseline was $144.1 / 83.8 \mathrm{mmHg}$. After a mean follow-up of 2.5 years, mean $\mathrm{BP}$ was 3.8/2.0 mmHg lower with telmisartan versus placebo. The addition of telmisartan to other antihypertensive therapy soon after an ischemic stroke and continued for 2.5 years did not significantly reduce the rate of recurrent stroke, major $\mathrm{CV}$ events, or new-onset diabetes compared with standard care.

Table I Cardiovascular-outcome trials with telmisartan and perindopril in patients with controlled blood pressure

\begin{tabular}{|c|c|c|c|c|c|}
\hline Study & Patients & Randomized (n) & Treatment & Duration & Primary outcome* \\
\hline EUROPA $^{31}$ & $\begin{array}{l}\text { Men and women } \\
\geq 18 \text { years without } \\
\text { HF and with CHD }\end{array}$ & 12,218 & $\begin{array}{l}\text { Perindopril } 8 \mathrm{mg} / \text { day } \\
\text { or matching placebo }\end{array}$ & $\begin{array}{l}\text { Mean } \\
\text { follow-up } \\
\text { of } 4.2 \text { years }\end{array}$ & $\begin{array}{l}\text { Superiority of perindopril versus placebo } \\
488(8 \%) \text { on perindopril; } 603(10 \%) \\
\text { on placebo } \\
\text { RRR } 20 \%, 95 \% \mathrm{Cl} 9-29\end{array}$ \\
\hline ONTARGET ${ }^{35}$ & $\begin{array}{l}\text { Patients with } \\
\text { coronary, peripheral, } \\
\text { or cerebrovascular } \\
\text { disease or diabetes } \\
\text { with end-organ } \\
\text { damage }\end{array}$ & 25,620 & $\begin{array}{l}\text { Ramipril } 10 \mathrm{mg} / \text { day; } \\
\text { telmisartan } 80 \mathrm{mg} / \text { day; } \\
\text { combination therapy } \\
\text { of ramipril } 10 \mathrm{mg} \text { plus } \\
\text { telmisartan } 80 \mathrm{mg}\end{array}$ & $\begin{array}{l}\text { Median } \\
\text { follow-up } \\
\text { of } 4.7 \text { years }\end{array}$ & $\begin{array}{l}\text { Noninferiority of telmisartan versus ramipril } \\
\text { I,4I } 2 \text { (I6.5\%) patients on ramipril; } \\
\text { I,423 (I6.7\%) patients on telmisartan } \\
\text { RR I.0I, } 95 \% \mathrm{Cl} 0.94-\mathrm{I} .09 \text { (versus ramipril) } \\
\text { Superiority of combination therapy versus } \\
\text { ramipril } \\
\text { I,386 (I6.3\%) patients on combination } \\
\text { RR } 0.99,95 \% \mathrm{Cl} 0.92-\mathrm{I} .07 \text { (versus ramipril) }\end{array}$ \\
\hline
\end{tabular}

Notes: *CV death, MI, or cardiac arrest in EUROPA; composite outcome of death from CV causes, MI, stroke, or hospitalization for HF in ONTARGET.

Abbreviations: $\mathrm{CHD}$, coronary heart disease; $\mathrm{Cl}$, confidence interval; $\mathrm{CV}$, cardiovascular; $\mathrm{HF}$, heart failure; $\mathrm{Ml}$, myocardial infarction; RR, risk reduction; RRR, relative risk reduction; EUROPA, EURopean trial On reduction of cardiac events with Perindopril in stable coronary Artery disease; ONTARGET, ONgoing Telmisartan Alone and in combination with Ramipril Global Endpoint Trial. 
A EUROPA study

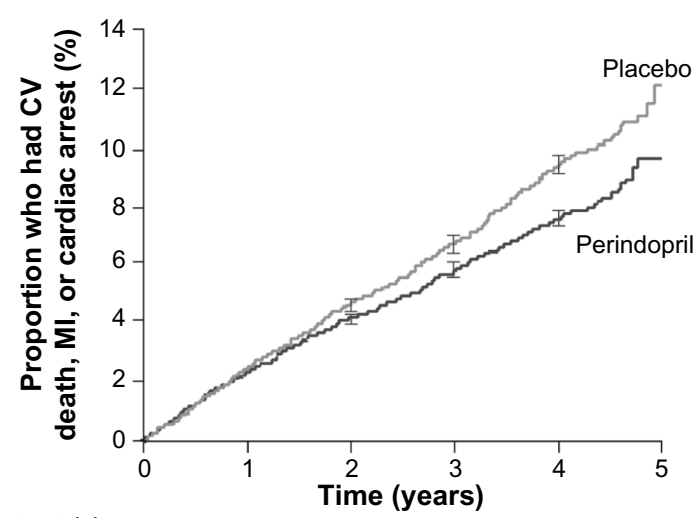

Patients at risk

$\begin{array}{lllllll}\text { Placebo } & 6,108 & 5,943 & 5,781 & 5,598 & 4,450 & 71\end{array}$ $\begin{array}{llllll}\text { Perindopril } & 6,110 & 5,957 & 5,812 & 5,653 & 4,515\end{array}$

C TRANSCEnD study

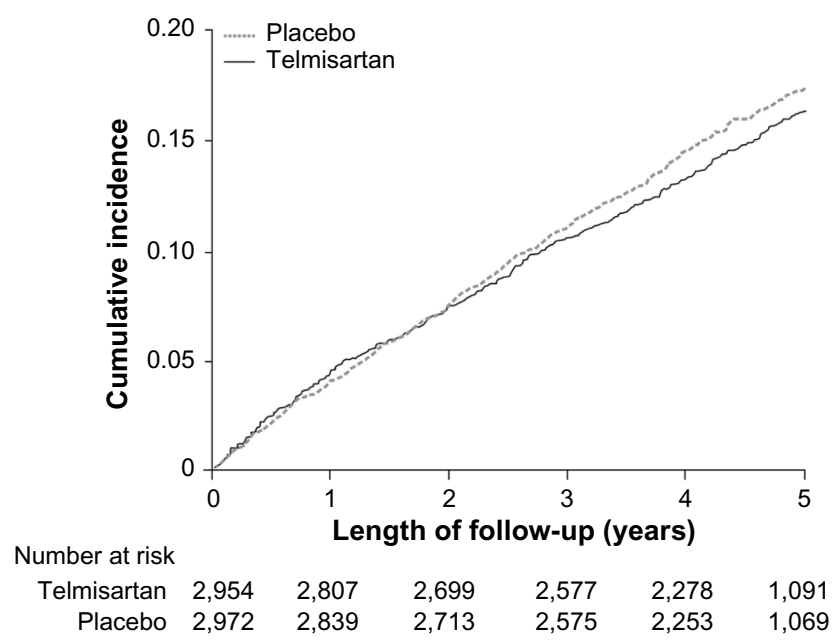

B ONTARGET study

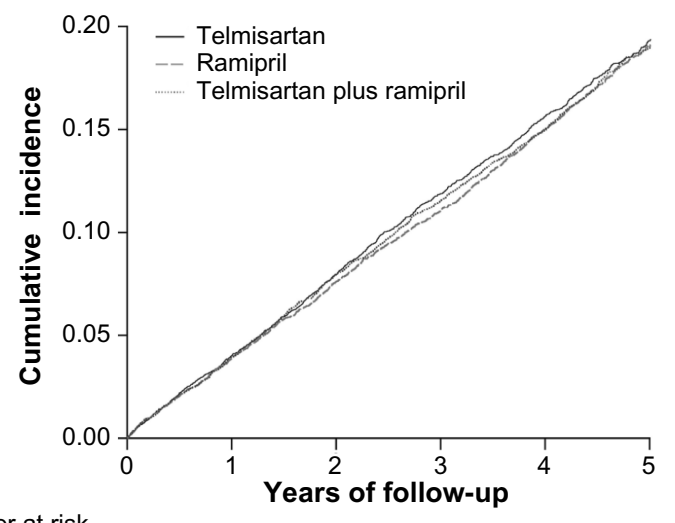

Number at risk

$\begin{array}{rrrrrrr}\text { Telmisartan } & 8,542 & 8,177 & 7,778 & 7,420 & 7,051 & 1,687 \\ \text { Ramipril } & 8,576 & 8,214 & 7,832 & 7,472 & 7,093 & 1,703 \\ \text { Telmisartan } & 8,502 & 8,133 & 7,738 & 7,375 & 7,022 & 1,718 \\ \text { plus ramipril } & & & & & & \end{array}$
plus ramipril

Figure 2 Primary outcome* results in the EUROPA, ${ }^{31}$ ONTARGET, ${ }^{35}$ and TRANSCEND ${ }^{33}$ studies. (A) The EUROPA study assessed superiority of perindopril versus placebo. (B) The ONTARGET study assessed noninferiority of telmisartan versus ramipril defined as an HR below the predefined margin. (C) The TRANSCEND study assessed whether telmisartan compared to placebo reduces the primary outcome occurrence in patients with CV disease or high-risk diabetes and without HF who are intolerant to ACE inhibitors.

Notes: *CV death, MI, or cardiac arrest in EUROPA; composite outcome of death from CV causes, MI, stroke, or hospitalization for HF in ONTARGET and TRANSCEND. (A) Reprinted from The Lancet, 362, Fox KM, Efficacy of perindopril in reduction of cardiovascular events among patients with stable coronary artery disease: randomised, doubleblind, placebo-controlled, multicentre trial (the EUROPA study), 782-788, copyright @ (2003), with permission from Elsevier. ${ }^{31}$ (B) Reprinted from rom N Engl J Med, Yusuf S, Teo KK, Pogue J, et al, Telmisartan, ramipril, or both in patients at high risk for vascular events, 358, I547-1559, copyright @ (2008) Massachusetts Medical Society. Reprinted with permission from Massachusetts Medical Society. ${ }^{35}$ (C) Reprinted from The Lancet, 372, Yusuf S, Teo K, Anderson C, et al, Effects of the angiotensin-receptor blocker telmisartan on cardiovascular events in high-risk patients intolerant to angiotensin-converting enzyme inhibitors: a randomised controlled trial, II74-1 I83, copyright (2008), with permission from Elsevier. ${ }^{33}$

Abbreviations: ACE, angiotensin-converting enzyme; CV, cardiovascular; EUROPA, EURopean trial On reduction of cardiac events with Perindopril in stable coronary Artery disease; HF, heart failure; HR, hazard ratio; MI, myocardial infarction; ONTARGET, ONgoing Telmisartan Alone and in combination with Ramipril Global Endpoint Trial; TRANSCEND, Telmisartan Randomized AssessmeNt Study in ACE-I iNtolerant subjects with cardiovascular Disease.

The fact that the trend toward a differential effect did not achieve statistical significance has been attributed to a lack of power and the factorial design, which led to significant treatment crossover. ${ }^{50}$ The shorter mean duration of the study may also have contributed to the lack of efficacy.

A post hoc exploratory analysis showed a lower rate of recurrent stroke with telmisartan versus standard care after 6 months. Similar results were demonstrated in the HOPE and PROGRESS trials, where little or no apparent CV benefits were seen in the first 6 months, followed thereafter by a gradual and continuous lowering in the rates of stroke and major CV events. Subdivision of data from the PRoFESS trial to focus only on the $40 \%$ of patients who were treated very soon after a stroke ( $\leq 10$ days) did not suggest a concentration of harm during the first 30 days of the study. ${ }^{34}$

Although the results of the PRoFESS trial appear to be inconsistent compared with those of the PROGRESS trial, where long-term lowering of BP reduced recurrent strokes, there are several distinct differences between the two studies. First, different patient populations were investigated in the 
two studies. PRoFESS investigated for the first time in a large outcome trial patients after recent stroke and even within the "vulnerable phase" (40\% within 10 days after stroke included, almost $70 \%$ within 1 month), where antihypertensive treatment was not recommended now and at that time. ${ }^{51}$ Second, at baseline, patients' mean BP was higher in the PROGRESS study $^{27}$ than in the PRoFESS study. Third, a majority of patients $(58 \%)$ in the PROGRESS study were assigned to receive a combination of perindopril + indapamide, which reduced BP to a substantial degree $(12.3 / 5.0 \mathrm{mmHg})$, compared with perindopril monotherapy $(4.9 / 2.8 \mathrm{mmHg})$. The reduction of stroke in the PROGRESS study was not seen among patients receiving perindopril monotherapy, despite $\mathrm{BP}$ reduction. Hence, the shorter duration of time since stroke onset, the smaller reduction in BP, and the lower initial BP levels can partially explain the apparent differences in the results compared with PROGRESS.

ONTARGET (ONgoing Telmisartan Alone and in combination with Ramipril Global Endpoint Trial ${ }^{35}$ was the first large head-to-head comparison study between telmisartan and ramipril, with proven $\mathrm{CV}$-protective benefits of the latter drug. The ONTARGET study followed the HOPE trial, in which ramipril was shown to reduce $\mathrm{CV}$ risk in a similar patient population compared with placebo. ${ }^{36}$ ONTARGET was a randomized, double-blind study conducted in patients with vascular disease or diabetes with end-organ damage, but mostly controlled BP (BP before run-in period was $141.8 / 82.1 \mathrm{mmHg}$ ) and no heart failure. A total of 25,620 patients were randomized to daily treatment with telmisartan $80 \mathrm{mg}$, ramipril $10 \mathrm{mg}$, or a combination of both agents, with a median follow-up of 56 months (Table 1). ${ }^{35}$ Mean BP was slightly and consistently lower with telmisartan versus ramipril $(-0.9 /-0.6 \mathrm{mmHg})$.

The primary outcome of death from CV causes, MI, stroke, or hospitalization for heart failure occurred in a similar percentage of patients on ramipril (16.5\%) and telmisartan (16.7\%) (Table 1 and Figure 2B); relative risk 1.01, 95\% CI $0.94-1.09 ; P=0.004$ for noninferiority. Similar results were also observed for the secondary outcome of CV death, $\mathrm{MI}$, or stroke (the primary end point in HOPE): ramipril $(14.1 \%)$ versus telmisartan $(13.9 \%)$ (relative risk $0.99,95 \%$ CI $0.91-1.07 ; P=0.001$ for noninferiority). The telmisartan group had lower rates of cough $(1.1 \%$ versus $4.2 \%, P<0.001)$ and angioedema $(0.1 \%$ versus $0.3 \%, P=0.01)$, but a higher rate of hypotensive symptoms $(2.6 \%$ versus $1.7 \%, P<0.001)$ than the ramipril group. ${ }^{35}$ The total number and the rate of discontinuations in the telmisartan group was significantly lower than in the ramipril group over the course of the trial $(23.0 \%$ versus $24.5 \%, P=0.02)^{35}$ (Figure 3 ). Combination therapy with

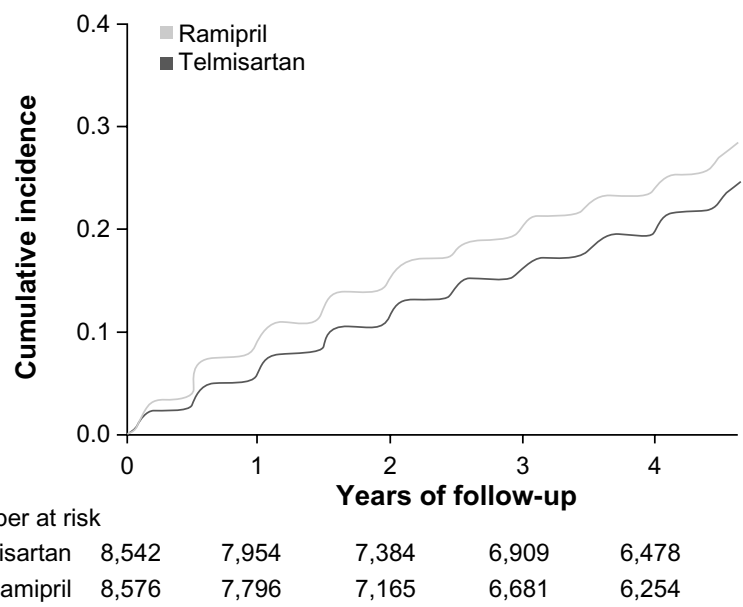

Figure 3 Discontinuation rates with telmisartan and ramipril in ONTARGET. Note: Reproduced from Sleight P. Clinical evidence from ONTARGET: the value of an angiotensin II receptor blocker and an angiotensin-converting enzyme inhibitor. J Hypertens Suppl. 2009;27(5):S23-S29.82 Wolters Kluwer Health/Lippincott Williams and Wilkins. Promotional and commercial use of the material in print, digital or mobile device format is prohibited with the permission from the publisher Lippincott Williams and Wilkins. Please contact journalpermissions@|ww.com for further information.

Abbreviation: ONTARGET, ONgoing Telmisartan Alone and in combination with Ramipril Global Endpoint Trial.

telmisartan and ramipril was associated with more adverse events without an increase in benefit, despite a greater reduction in $\mathrm{BP} .^{35}$ The composite renal outcome events of dialysis, doubling of serum creatinine, and death, were similar between telmisartan and ramipril. Increase in albuminuria was significantly reduced with telmisartan compared with ramipril $(P=0.004)$, while estimated glomerular filtration rate declined least with ramipril compared with telmisartan $(P<0.0001){ }^{52}$ Overall, the authors concluded that telmisartan has similar beneficial effects on kidney function as ramipril.

TRANSCEND (Telmisartan Randomised AssessmeNt Study in ACE iNtolerant subjects with cardiovascular Disease $)^{33}$ was the first study to observe the effect of an ARB (telmisartan) in patients intolerant to an ACE inhibitor. In TRANSCEND, ${ }^{33} 5,926$ patients intolerant to ACE inhibitors were randomized to telmisartan $80 \mathrm{mg}$ daily or placebo in addition to standard therapies for a medium follow-up of 56 months. Mean baseline BP of the randomized patients was 141.0/81.9 mmHg. Mean BP was lower on telmisartan than it was on placebo during the study (mean weighted difference of 4.0/2.2 $\mathrm{mmHg}$ between groups). Fewer patients on telmisartan experienced the primary outcome of death from CV causes, MI, stroke, or hospitalization for heart failure compared to placebo, but the difference was not significant $(15.7 \%$ versus $17.0 \%$, hazard ratio $0.92,95 \%$ CI $0.81-1.05 ; P=0.216$ ) (Figure $2 \mathrm{C}) .{ }^{33}$ The study was underpowered, as there was a lower incidence of $\mathrm{CV}$ events than assumed in power calculations, which were based upon the HOPE trial; this was probably due to higher use of background therapy, such as aspirin and statins, 
in ONTARGET/TRANSCEND. ${ }^{53}$ However, the secondary outcome of CV death, MI, or stroke occurred in significantly fewer patients on telmisartan compared to placebo $(13.0 \%$ versus $14.8 \%$, hazard ratio $0.87,95 \%$ CI $0.76-1.00 ; P=0.048$ ). There was a decrease of $8 \%$ in primary end-point events and $13 \%$ in secondary end-point events with telmisartan compared to placebo. Telmisartan was well tolerated in this population of ACE inhibitor-intolerant patients. ${ }^{33}$

\section{Discussion}

Telmisartan and perindopril have both been shown to be efficacious in the treatment of hypertension and to reduce CV risk. In head-to-head comparison trials, telmisartan has somewhat better antihypertensive efficacy than perindopril, although the relative difference in BP reduction is small. ${ }^{22,23}$ Superior BP control with telmisartan compared with perindopril and other ACE inhibitors, such as ramipril, lisinopril, and enalapril, was also observed in a meta-analysis of randomized, controlled trials in patients with hypertension. ${ }^{54}$ Both telmisartan and perindopril provide sustained 24-hour efficacy, ${ }^{14,15}$ which is as important as the magnitude of BP reductions ${ }^{52,55-58}$ in the prevention of $\mathrm{CV}$ and cerebrovascular events; however, telmisartan, as with all ARBs, is associated with fewer drug-related adverse events and better tolerability compared with perindopril and other ACE inhibitors. ${ }^{54,59}$ Low treatment adherence is one of the main causes for poor BP control ${ }^{12}$ and increased CV risks. ${ }^{60,61}$ Treatment with telmisartan apparently results in better treatment adherence compared with ACE inhibitors. ${ }^{59}$

The evidence for CV benefits with perindopril has been mainly demonstrated in patients with hypertension, with combination therapy, and in placebo-controlled trials. The large reductions in BP observed in these trials and the lack of an active control makes it difficult to conclude whether the $\mathrm{CV}$ benefits were due to the reduction in BP or were beyond-BP-lowering benefits. Even the EUROPA trial was compromised by differences in achieved BP. Although these differences can be statistically adjusted, they reduce confidence in whether the effect is genuinely beyond BP lowering. Furthermore, perindopril monotherapy did not prevent stroke, despite BP reduction in EUROPA and PROGRESS, and did not reduce the incidence of revascularization in EUROPA. A review of the results from ASCOT-BPLA, PROGRESS, and EUROPA ${ }^{62}$ also suggested that the reduction of $\mathrm{CV}$ events by perindopril was in large part associated with BP reduction, with greater $\mathrm{BP}$ reduction associated with greater reduction in $\mathrm{CV}$ events in these studies. The reduction of $\mathrm{CV}$ events was maximized when perindopril was combined with either amlodipine or indapamide. The PREAMI trial ${ }^{30}$ had a short duration of 1 year for an outcome trial, and was not associated with better clinical outcomes, even though perindopril treatment was found to reduce progressive left ventricular remodeling.

In contrast to $\mathrm{CV}$-outcome studies of perindopril, studies with telmisartan have been conducted in patients with controlled BP at baseline. ONTARGET is the largest and the only clinical study to compare the $\mathrm{CV}$ protection of an ACE inhibitor to an ARB in a head-to-head comparison design. There were minimal BP differences at end point, and active monotherapies were compared. The primary and secondary outcomes, ${ }^{35}$ as well as composite renal outcomes, ${ }^{52}$ occurred in a similar percentage of patients on telmisartan and ramipril. In the TRANSCEND study ${ }^{33}$ the primary outcome occurred in fewer patients on telmisartan than placebo, but the difference was not statistically significant; the secondary outcome of CV death, MI, or stroke occurred in significantly fewer patients on telmisartan compared to placebo, and telmisartan was well tolerated by the ACE inhibitor-intolerant patients included in this trial. ${ }^{33}$ Based on these findings, telmisartan is the only ARB approved for the reduction of $\mathrm{CV}$ morbidity in patients with manifest atherothrombotic $\mathrm{CV}$ disease (history of CHD, stroke, or peripheral artery disease) or diabetes mellitus, with documented target-organ damage. ${ }^{15}$ The lack of efficacy with telmisartan in PRoFESS has been attributed to the factorial design, lack of statistical power, and the short duration of the trial due to early termination. ${ }^{50}$ In PROGRESS, perindopril monotherapy had no effect on stroke occurrence, and resulted in a modest reduction in BP compared with combination therapy. ${ }^{27}$ Similar results were found in the EUROPA trial regarding prevention of stroke with perindopril.

Another post hoc observational analysis of PRoFESS showed that among patients with recent noncardioembolic ischemic stroke, SBP levels during follow-up in the very lownormal ( $<120 \mathrm{mmHg}$ ), high (140 to $<150 \mathrm{mmHg}$ ), or very high ( $\geq 150 \mathrm{mmHg}$ ) range were associated with increased risk of recurrent stroke. The J-shaped association of SBP with recurrent vascular risk after stroke was most pronounced in the first 90-180 days after the qualifying event. ${ }^{63}$ In COSSACS (Continue or Stop post-Stroke Antihypertensives Collaborative Study), in patients who were enrolled within 48 hours of stroke and the last dose of antihypertensive drug, no substantial differences were observed after 2 weeks in rates of serious adverse events, 6-month mortality, or major CV events between groups who continued or stopped preexisting antihypertensive drug regimens. ${ }^{64}$ 
Other CV-protective benefits have also been observed with telmisartan and perindopril. Telmisartan and perindopril had beneficial antithrombotic effects in addition to significantly reducing or normalizing BP in patients with untreated mild-to-moderate essential hypertension after 1 month of treatment. ${ }^{26}$ Telmisartan is superior to perindopril in improving arterial stiffness in hypertensive patients, ${ }^{65}$ and is more effective than perindopril at raising adiponectin levels and suppressing aldosterone in patients with essential hypertension. ${ }^{66}$ In PERTINENT (PERindopril-Thrombosis, InflammatioN, Endothelial dysfunction, and Neurohormonal activation Trial), a substudy of EUROPA, perindopril was reported to improve endothelial dysfunction by increasing bradykinin and reducing angiotensin II levels ${ }^{67}$ In patients with coronary artery disease, perindopril is suggested to have an advantage over other ACE inhibitors at the level of tissue ACE inhibition and relative selectivity for bradykinin. ${ }^{6}$ Increased bradykinin levels lead to activation of proinflammatory peptides and a local release of histamine, resulting in cough-reflex hypersensitivity. ${ }^{69}$

A number of meta-analyses have compared ARBs and ACE inhibitors as a class, with varying results, depending on the trials included in the meta-analyses. ARBs and ACE inhibitors have both been reported to be equally effective in reducing the risk of $\mathrm{MI}, \mathrm{CV}$ mortality, and total mortality; ${ }^{53,70,71}$ in the prevention of atrial fibrillation ${ }^{72}$ and reduction of newly diagnosed type 2 diabetes incidence, ${ }^{73}$ and ARBs were found to be more effective than ACE inhibitors in stroke prevention. ${ }^{71} \mathrm{~A}$ meta-analysis of nine randomized trials comparing treatments in 62,605 hypertensive patients did not show beyond-BP-lowering benefits for ACE inhibitors. ${ }^{74}$ A pooled analysis of $20 \mathrm{CV}$ mortality-morbidity trials showed that treatment with RAS inhibitors as a class resulted in a significant $5 \%$ relative reduction in all-cause mortality in populations with a high prevalence of hypertension, but the benefit was largely due to ACE inhibitors, and ARBs had a neutral effect. ${ }^{75}$ The analysis also showed that mortality reduction was larger in trials with a higher baseline SBP and in those with the largest mean SBP reduction at the end of treatment. It should be noted, however, that the trials that showed the largest benefit for ACE inhibitors in the metaanalysis used treatment protocols in which the ACE inhibitor was second-line, such as ASCOT-BPLA and HYVET. ${ }^{76}$

Another recent meta-analysis of placebo-controlled trials in high-risk patients without heart failure showed ACE inhibitors as a class reduced all-cause and CV deaths, as well as CV morbidity and new-onset diabetes mellitus, while ARBs reduced the composite outcome of $\mathrm{CV}$ death,
MI, and stroke and the risk of new-onset diabetes mellitus, but not the risk of all-cause death, MI, and new-onset heart failure. ${ }^{77}$ The ACE-inhibitor trials included in the analysis were mostly conducted in patients with coronary or other vascular atherosclerotic disease, and ARB trials were mostly conducted in patients with diabetes mellitus or impaired glucose tolerance. ${ }^{77}$

The ESH/ESC guidelines state that the superiority of one class of agents over another for some outcomes observed in various meta-analyses is largely dependent on the selection bias of trials, and the largest meta-analyses available do not show clinically relevant differences between drug classes. ${ }^{12}$ Meta-analysis is a statistical tool mostly used to pool data from small studies to generate a hypothesis and calculate the number of patients needed to test the generated hypothesis in large-scale, randomized, controlled trials. ${ }^{78}$ Meta-analyses have flaws, which include but are not limited to publication bias, selection of studies, different study populations, and available therapeutic options. ${ }^{78-80}$ Differences between metaanalyses may also be partially explained by variation between the different drugs within each class. For example, in a recent retrospective cohort study involving a large number of diabetes patients aged $>66$ years on ARBs, treatment with telmisartan and valsartan was associated with a lower risk of admission to hospital for acute MI, stroke, or heart failure compared with candesartan, irbesartan, and losartan, suggesting intraclass differences in efficacy. ${ }^{81}$ For these reasons, the best evidence is derived from large, randomized, controlled, clinical trials, although there are few such trials in patients without heart failure (ONTARGET ${ }^{35}$ being a notable exception). Although meta-analyses provide important information on class effects, the best approach for treatments tailored to individual patient needs should take into account the evidence base for specific drugs, rather than recommendations based on "class effect" for achieving therapeutic targets.

\section{Conclusion}

Hypertension is a major $\mathrm{CV}$ risk factor, and BP-lowering strategies substantially reduce the risk. ACE inhibitors and ARBs are both recommended as first-line treatment options for hypertension. Both classes of drugs also have proven CV-protective benefits, although it is likely that these vary between the different drugs within each class as a result of pharmacologic differences. The trials reviewed here show perindopril and telmisartan are both long-acting antihypertensive drugs, with proven antihypertensive efficacy and tolerability, and are supported by substantial evidence from $\mathrm{CV}$-outcome trials. Importantly, however, the evidence for 
perindopril derives from trials in patients with hypertension (in whom effects due to BP lowering are mixed with other pharmacologic effects), while the evidence for $\mathrm{CV}$ protection with telmisartan comes from patients with controlled BP.

\section{Acknowledgments}

The authors were fully responsible for all content and editorial decisions, were involved at all stages of manuscript development, and have approved the final version. Medical writing assistance, supported financially by Boehringer Ingelheim Pharma $\mathrm{GmbH}$ and $\mathrm{Co} \mathrm{KG}$, was provided by Lakshmi Venkatraman, PhD and Tom Rees, PhD of Parexel during the preparation of this article. The authors meet criteria for authorship, as recommended by the International Committee of Medical Journal Editors, and received no compensation related to the development of the manuscript. Boehringer Ingelheim Pharma $\mathrm{GmbH}$ and $\mathrm{Co} \mathrm{KG}$ was given the opportunity to check the data used in the manuscript for factual accuracy only.

\section{Disclosure}

Dr Wang has received consulting fees or honoraria and support for travel from Boehringer Ingelheim and payment for lectures, including service on speakers' bureaus from Merck, Sharpe and Dohme, Novartis, Omron, Pfizer, Servier, and Takeda. Dr Chwallek is an employee of Boehringer Ingelheim. Dr Pimenta was an employee of Boehringer Ingelheim at the time of the study.

\section{References}

1. Atlas SA. The renin-angiotensin aldosterone system: pathophysiological role and pharmacologic inhibition. J Manag Care Pharm. 2007; 13(8 Suppl B):9-20.

2. Montani JP, Van Vliet BN. General physiology and pathophysiology of the renin-angiotensin system. In: Unger T, Schölkens BA, editors. Angiotensin Vol. II. Heidelberg: Springer; 2004:548.

3. Dzau V.The cardiovascular continuum and renin-angiotensin-aldosterone system blockade. J Hypertens Suppl. 2005;23(1):S9-S17.

4. Unger $\mathrm{T}$. The role of the renin-angiotensin system in the development of cardiovascular disease. Am J Cardiol. 2002;89(2A):3A-9A.

5. Asmar R. Telmisartan in high cardiovascular risk patients. Eur Cardiol Rev. 2012;8(1):10-16.

6. Schmieder RE, Hilgers KF, Schlaich MP, Schmidt BM. Renin-angiotensin system and cardiovascular risk. Lancet. 2007;369(9568):1208-1219.

7. Verdecchia P, Gentile G, Angeli F, Reboldi G. Beyond blood pressure: evidence for cardiovascular, cerebrovascular, and renal protective effects of renin-angiotensin system blockers. Ther Adv Cardiovasc Dis. 2012;6(2):81-91.

8. [No authors listed]. KDIGO clinical practice guideline for the management of blood pressure in chronic kidney disease. Kidney Int Suppl. 2012;2(5):338-414.

9. Berl T. Angiotensin-converting enzyme inhibitors versus AT1 receptor antagonist in cardiovascular and renal protection: the case for AT1 receptor antagonist. J Am Soc Nephrol. 2004;15 Suppl 1:S71-S76.

10. Poulter N. ARBs in hypertension. Br J Cardiol. 2010;17:s6-s9.
11. American Diabetes Association. Standards of medical care in diabetes 2013. Diabetes Care. 2013;36 Suppl 1:S11-S66.

12. Mancia G, Fagard R, Narkiewicz K, et al. 2013 ESH/ESC guidelines for the management of arterial hypertension: the Task Force for the management of arterial hypertension of the European Society of Hypertension (ESH) and of the European Society of Cardiology (ESC). Eur Heart J. 2013;31(7):1281-1357.

13. McMurray JJ, Adamopoulos S, Anker SD, et al. ESC Guidelines for the diagnosis and treatment of acute and chronic heart failure 2012: The Task Force for the Diagnosis and Treatment of Acute and Chronic Heart Failure 2012 of the European Society of Cardiology. Developed in collaboration with the Heart Failure Association (HFA) of the ESC. Eur Heart J. 2012;33(14):1787-1847.

14. Servier Laboratories. Coversyl (arginine): summary of product characteristics. Neuilly-sur-Seine, France: Servier Laboratories; 2009.

15. Boehringer Ingelheim. Micardis (telmisartan) tablets [prescribing information]. Ingelheim, Germany: Boehringer Ingelheim; 2011.

16. Maillard MP, Perregaux $C$, Centeno $C$, et al. In vitro and in vivo characterization of the activity of telmisartan: an insurmountable angiotensin II receptor antagonist. J Pharmacol Exp Ther. 2002;302(3):1089-1095.

17. Battershill AJ, Scott LJ. Telmisartan: a review of its use in the management of hypertension. Drugs. 2006;66(1):51-83.

18. Hurst M, Jarvis B. Perindopril: an updated review of its use in hypertension. Drugs. 2001;61(6):867-896.

19. Sharpe M, Jarvis B, Goa KL. Telmisartan: a review of its use in hypertension. Drugs. 2001;61(10):1501-1529.

20. Thomson A, Greenacre M. Perindopril: the evidence of its therapeutic impact in hypertension. Core Evid. 2007;2(1):63-79.

21. Todd PA, Fitton A. Perindopril. A review of its pharmacological properties and therapeutic use in cardiovascular disorders. Drugs. 1991;42(1):90-114.

22. Nalbantgil I, Nalbantgil S, Ozerkan F, et al. The efficacy of telmisartan compared with perindopril in patients with mild-to-moderate hypertension. Int J Clin Pract Suppl. 2004;(145):50-54.

23. Ragot S, Ezzaher A, Meunier A, Poterre M, Bourkaib R, Herpin D. Comparison of trough effect of telmisartan vs perindopril using self blood pressure measurement: EVERESTE study. J Hum Hypertens. 2002;16(12):865-873.

24. Ghiadoni L, Magagna A, Versari D, et al. Different effect of antihypertensive drugs on conduit artery endothelial function. Hypertension. 2003;41(6):1281-1286.

25. Peng X, Lin Z, Zhao Y, Huang P. Effect of telmisartan on left ventricular hypertrophy in elderly patients with diabetes mellitus and essential hypertension. Zhonghua Lao Nian Yi Xue Za Zhi. 2005;24(6): 435-437.

26. Remková A, Kratochvíl'ova H, Durina J. Impact of the therapy by renin-angiotensin system targeting antihypertensive agents perindopril versus telmisartan on prothrombotic state in essential hypertension. J Hum Hypertens. 2008;22(5):338-345.

27. PROGRESS Collaborative Group. Randomised trial of a perindoprilbased blood-pressure-lowering regimen among 6,105 individuals with previous stroke or transient ischaemic attack. Lancet. 2001;358(9287): 1033-1041.

28. Cleland JG, Tendera M, Adamus J, Freemantle N, Polonski L, Taylor J. The perindopril in elderly people with chronic heart failure (PEP-CHF) study. Eur Heart J. 2006;27(19):2338-2345.

29. Dahlof B, Sever PS, Poulter NR, et al. Prevention of cardiovascular events with an antihypertensive regimen of amlodipine adding perindopril as required versus atenolol adding bendroflumethiazide as required, in the Anglo-Scandinavian Cardiac Outcomes Trial - Blood Pressure Lowering Arm (ASCOT-BPLA): a multicentre randomised controlled trial. Lancet. 2005;366(9489):895-906.

30. Ferrari R. Effects of angiotensin-converting enzyme inhibition with perindopril on left ventricular remodeling and clinical outcome: results of the randomized Perindopril and Remodeling in Elderly with Acute Myocardial Infarction (PREAMI) study. Arch Intern Med. 2006;166(6): 659-666. 
31. Fox KM. Efficacy of perindopril in reduction of cardiovascular events among patients with stable coronary artery disease: randomised, doubleblind, placebo-controlled, multicentre trial (the EUROPA study). Lancet. 2003;362(9386):782-788.

32. Patel A, MacMahon S, Chalmers J, et al. Effects of a fixed combination of perindopril and indapamide on macrovascular and microvascular outcomes in patients with type 2 diabetes mellitus (the ADVANCE trial): a randomised controlled trial. Lancet. 2007;370(9590):829-840.

33. Yusuf S, Teo K, Anderson C, et al. Effects of the angiotensin-receptor blocker telmisartan on cardiovascular events in high-risk patients intolerant to angiotensin-converting enzyme inhibitors: a randomised controlled trial. Lancet. 2008;372(9644):1174-1183.

34. Yusuf S, Diener HC, Sacco RL, et al. Telmisartan to prevent recurrent stroke and cardiovascular events. $N$ Engl J Med. 2008;359(12): 1225-1237.

35. Yusuf S, Teo KK, Pogue J, et al. Telmisartan, ramipril, or both in patients at high risk for vascular events. N Engl J Med. 2008;358(15): 1547-1559.

36. Yusuf S, Sleight P, Pogue J, Bosch J, Davies R, Dagenais G. Effects of an angiotensin-converting-enzyme inhibitor, ramipril, on cardiovascular events in high-risk patients. The Heart Outcomes Prevention Evaluation Study Investigators. N Engl J Med. 2000;342(3):145-153.

37. Staessen JA, Wang J. Blood-pressure lowering for the secondary prevention of stroke. Lancet. 2001;358(9287):1026-1027.

38. Beckett NS, Peters R, Fletcher AE, et al. Treatment of hypertension in patients 80 years of age or older. $N$ Engl $\mathrm{J} \mathrm{Med}$. 2008;358(18): 1887-1898.

39. Beckett N, Peters R, Tuomilehto J, et al. Immediate and late benefits of treating very elderly people with hypertension: results from active treatment extension to Hypertension in the Very Elderly randomised controlled trial. BMJ. 2012;344:d7541.

40. Mancia G, Laurent S, Agabiti-Rosei E, et al. Reappraisal of European guidelines on hypertension management: a European Society of Hypertension Task Force document. J Hypertens. 2009;27(11):2121-2158.

41. Kaplan NM. Vascular outcome in type 2 diabetes: an ADVANCE? Lancet. 2007;370(9590):804-805.

42. Julius S, Kjeldsen SE, Weber M, et al. Outcomes in hypertensive patients at high cardiovascular risk treated with regimens based on valsartan or amlodipine: the VALUE randomised trial. Lancet. 2004;363(9426): 2022-2031.

43. Weber MA, Julius S, Kjeldsen SE, et al. Blood pressure dependent and independent effects of antihypertensive treatment on clinical events in the VALUE Trial. Lancet. 2004;363(9426):2049-2051.

44. Williams B, Lacy PS, Thom SM, et al. Differential impact of blood pressure-lowering drugs on central aortic pressure and clinical outcomes: principal results of the Conduit Artery Function Evaluation (CAFE) study. Circulation. 2006;113(9):1213-1225.

45. Jamerson K, Weber MA, Bakris GL, et al. Benazepril plus amlodipine or hydrochlorothiazide for hypertension in high-risk patients. $N$ Engl J Med. 2008;359(23):2417-2428.

46. Neldam S, Edwards C. Telmisartan plus HCTZ vs amlodipine plus HCTZ in older patients with systolic hypertension: results from a large ambulatory blood pressure monitoring study. Am J Geriatr Cardiol. 2006;15(3):151-160.

47. Neutel JM, Mancia G, Black HR, et al. Single-pill combination of telmisartan/amlodipine in patients with severe hypertension: results from the TEAMSTA severe HTN study. J Clin Hypertens (Greenwich). 2012;14(4):206-215

48. Sharma AM, Davidson J, Koval S, Lacourciere Y. Telmisartan/ hydrochlorothiazide versus valsartan/hydrochlorothiazide in obese hypertensive patients with type 2 diabetes: the SMOOTH study. Cardiovasc Diabetol. 2007;6:28.

49. European Commission. Annex II: Scientific conclusions and grounds for amendment of the summary of product characteristics presented by the EMEA. Available from: http:/ec.europa.eu/health/ documents/community-register/2005/2005110710227/anx_10227_ en.pdf. Accessed February 28, 2014.
50. McInnes GT. Telmisartan to prevent recurrent stroke: the PRoFESS study: was the baby thrown out with the bathwater? Stroke. 2009;40(5): 1938-1940.

51. Adams HP Jr, del ZG, Alberts MJ, et al. Guidelines for the early management of adults with ischemic stroke: a guideline from the American Heart Association/American Stroke Association Stroke Council, Clinical Cardiology Council, Cardiovascular Radiology and Intervention Council, and the Atherosclerotic Peripheral Vascular Disease and Quality of Care Outcomes in Research Interdisciplinary Working Groups: the American Academy of Neurology affirms the value of this guideline as an educational tool for neurologists. Stroke. 2007;38(5):1655-1711.

52. Mann JF, Schmieder RE, McQueen M, et al. Renal outcomes with telmisartan, ramipril, or both, in people at high vascular risk (the ONTARGET study): a multicentre, randomised, double-blind, controlled trial. Lancet. 2008;372(9638):547-553.

53. Dagenais GR. Vascular protection: telmisartan in the ONTARGET trial programme. Eur Heart J Suppl. 2009;11 Suppl F:F47-F53.

54. Zou Z, Xi GL, Yuan HB, Zhu QF, Shi XY. Telmisartan versus angiotension [sic]-converting enzyme inhibitors in the treatment of hypertension: a meta-analysis of randomized controlled trials. J Hum Hypertens. 2009;23(5):339-349.

55. Dolan E, Stanton A, Thijs L, et al. Superiority of ambulatory over clinic blood pressure measurement in predicting mortality: the Dublin outcome study. Hypertension. 2005;46(1):156-161.

56. White WB. Ambulatory blood pressure as a predictor of target organ disease and outcome in the hypertensive patient. Blood Press Monit. 1999;4(3-4):181-184

57. Turnbull F. Effects of different blood-pressure-lowering regimens on major cardiovascular events: results of prospectively-designed overviews of randomised trials. Lancet. 2003;362(9395):1527-1535.

58. Wang JG, Li Y, Franklin SS, Safar M. Prevention of stroke and myocardial infarction by amlodipine and angiotensin receptor blockers: a quantitative overview. Hypertension. 2007;50(1):181-188.

59. Mancia G, Schumacher H. Incidence of adverse events with telmisartan compared with ACE inhibitors: evidence from a pooled analysis of clinical trials. Patient Prefer Adherence. 2012;6:1-9.

60. Esposti LD, Saragoni S, Benemei S, et al. Adherence to antihypertensive medications and health outcomes among newly treated hypertensive patients. Clinicoecon Outcomes Res. 2011;3:47-54.

61. Mazzaglia G, Ambrosioni E, Alacqua M, et al. Adherence to antihypertensive medications and cardiovascular morbidity among newly diagnosed hypertensive patients. Circulation. 2009;120(16):1598-1605.

62. Campbell DJ. A review of perindopril in the reduction of cardiovascular events. Vasc Health Risk Manag. 2006;2(2):117-124.

63. Ovbiagele B, Diener HC, Yusuf S, et al. Level of systolic blood pressure within the normal range and risk of recurrent stroke. JAMA. 2011;306(19):2137-2144.

64. Robinson TG, Potter JF, Ford GA, et al. Effects of antihypertensive treatment after acute stroke in the Continue or Stop Post-Stroke Antihypertensives Collaborative Study (COSSACS): a prospective, randomised, open, blinded-endpoint trial. Lancet Neurol. 2010;9(8): $767-775$.

65. Li Y, Ma SM, Du M, Chu WW, Cheng XM. Perindopril, amlodipine and telmisartan improve arterial stiffness in patients with hypertension. Zhonghua Xin Xue Guan Bing Za Zhi. 2009;37(10):908-912.

66. Nakamura T, Kawachi K, Saito Y, et al. Effects of ARB or ACEinhibitor administration on plasma levels of aldosterone and adiponectin in hypertension. Int Heart J. 2009;50(4):501-512.

67. Ceconi C, Fox KM, Remme WJ, et al. ACE inhibition with perindopril and endothelial function. Results of a substudy of the EUROPA study: PERTINENT. Cardiovasc Res. 2007;73(1):237-246.

68. Tardif JC. Angiotensin-converting enzyme inhibitors and atherosclerotic plaque: a key role in the cardiovascular protection of patients with coronary artery disease. Eur Heart J Supp. 2009;11 (Suppl E):E9-E16.

69. Karlberg BE. Cough and inhibition of the renin-angiotensin system. J Hypertens Suppl. 1993;11(3):S49-SS52. 
70. Bangalore S, Kumar S, Wetterslev J, Messerli FH. Angiotensin receptor blockers and risk of myocardial infarction: meta-analyses and trial sequential analyses of 147020 patients from randomised trials. BMJ. 2011;342:d2234.

71. Reboldi G, Angeli F, Cavallini C, Gentile G, Mancia G, Verdecchia P. Comparison between angiotensin-converting enzyme inhibitors and angiotensin receptor blockers on the risk of myocardial infarction, stroke and death: a meta-analysis. J Hypertens. 2008;26(7):1282-1289.

72. Healey JS, Baranchuk A, Crystal E, et al. Prevention of atrial fibrillation with angiotensin-converting enzyme inhibitors and angiotensin receptor blockers: a meta-analysis. J Am Coll Cardiol. 2005;45(11): 1832-1839.

73. Abuissa H, Jones PG, Marso SP, O’Keefe JH Jr. Angiotensin-converting enzyme inhibitors or angiotensin receptor blockers for prevention of type 2 diabetes: a meta-analysis of randomized clinical trials. $\mathrm{J} \mathrm{Am}$ Coll Cardiol. 2005;46(5):821-826.

74. Staessen JA, Wang JG, Thijs L. Cardiovascular protection and blood pressure reduction: a meta-analysis. Lancet. 2001;358(9290): 1305-1315.

75. van Vark LC, Bertrand M, Akkerhuis KM, et al. Angiotensinconverting enzyme inhibitors reduce mortality in hypertension: a meta-analysis of randomized clinical trials of renin-angiotensinaldosterone system inhibitors involving 158,998 patients. Eur Heart J. 2012;33(16):2088-2097.
76. Donzelli A. Reduction in all-cause mortality: from ACE inhibitors or from associated drugs? Eur Heart J. Epub June 25, 2012.

77. Savarese G, Costanzo P, Cleland JG, et al. A meta-analysis reporting effects of angiotensin-converting enzyme inhibitors and angiotensin receptor blockers in patients without heart failure. J Am Coll Cardiol. 2013;61(2):131-142.

78. Borzak S, Ridker PM. Discordance between meta-analyses and large-scale randomized, controlled trials. Examples from the management of acute myocardial infarction. Ann Intern Med. 1995;123(11): 873-877.

79. Feinstein AR. Meta-analysis: statistical alchemy for the 21 st century. J Clin Epidemiol. 1995;48(1):71-79.

80. Messerli FH. Case-control study, meta-analysis, and bouillabaisse: putting the calcium antagonist scare into context. Ann Intern Med. 1995;123(11):888-889.

81. Antoniou T, Camacho X, Yao Z, Gomes T, Juurlink DN, Mamdani MM. Comparative effectiveness of angiotensin-receptor blockers for preventing macrovascular disease in patients with diabetes: a population-based cohort study. CMAJ. 2013;185(12):1035-1041.

82. Sleight P. Clinical evidence from ONTARGET: the value of an angiotensin II receptor blocker and an angiotensin-converting enzyme inhibitor. J Hypertens Suppl. 2009;27(5):S23-S29.
Vascular Health and Risk Management

\section{Publish your work in this journal}

Vascular Health and Risk Management is an international, peerreviewed journal of therapeutics and risk management, focusing on concise rapid reporting of clinical studies on the processes involved in the maintenance of vascular health; the monitoring, prevention and treatment of vascular disease and its sequelae; and the involvement of

\section{Dovepress}

metabolic disorders, particularly diabetes. This journal is indexed on PubMed Central and MedLine. The manuscript management system is completely online and includes a very quick and fair peer-review system, which is all easy to use. Visit http://www.dovepress.com/ testimonials.php to read real quotes from published authors. 